\title{
PATRIMONIOS EN DISPUTA: ACERVOS NACIONALES, INVESTIGACIÓN ARQUEOLÓGICA Y RECLAMOS ÉTNICOS SOBRE RESTOS HUMANOS
}

\author{
CONTESTED HERITAGES: NATIONAL COLLECTIONS, ARCHAEOLOGICAL RESEARCH \\ AND ETHNIC CLAIMS ABOUT HUMAN REMAINS
}

MARÍA LUZ ENDERE (*)

\section{RESUMEN}

En las últimas décadas los reclamos de pueblos indígenas y minorías étnicas sobre restos humanos de sus antepasados hallados en sitios arqueológicos o depositados en museos se han convertido en un fenómeno que ha alcanzado escala mundial, en el marco de reivindicaciones étnicas de todo tipo. Aún cuando estos reclamos han sido efectuados en contextos muy diferentes (e.g. pueblos nativos americanos; judíos en Israel, etc.), han desafiado valores que parecerían indiscutibles, como el progreso de la investigación científica y el rol de los estados nacionales como guardianes del patrimonio cultural.

En este trabajo se analiza el desarrollo y evolución de la cuestión de las reinhumaciones en distintos países y se discuten las implicancias legales, profesionales y éticas del mismo para la arqueología y la gestión del patrimonio cultural.

\begin{abstract}
In recent decades the claims made by Indigenous peoples and ethnic minorities about the human remains of their ancestors, found in archaeological sites or held in museums, have become a world scale phenomenon, as part of a whole range of ethnic restitutions. Even though these claims have been made in very different contexts (e.g. Native American peoples, Jewish in Israel, etc.), they have challenged values which seemed to be indisputable, such as the progress of scientific research and the role of nation states as guardians of the cultural heritage. The aims of this pa-
\end{abstract}

(*) INCUAPA, Dpto. de Arqueología. Facultad de Ciencias Sociales. UNCPBA. Avda. del Valle 5737. B7400JWI Olavarría. Argentina.

El artículo fue remitido en su versión final el 3-II-00. per consist in analysing the development and the evolution of the reburial issue in different countries as well as discussing the legal, professional and ethical implications of this topic for archaeology and cultural heritage management.

Palabras claves: Reinhumaciones. Repatriación. Tratamiento ético de restos humanos. Patrimonio nacional. Gestión de los recursos arqueológicos.

Key words: Reburial. Repatriation. Ethical treatment of human remains. National heritage. Archaeological heritage management.

\section{INTRODUCCIÓN}

Los arqueólogos de comienzo de siglo habrían sido probablemente capaces de imaginar los avances tecnológicos con que cuenta hoy la arqueología para la exploración en el campo, así como de suponer que los adelantos de la ciencia iban a permitir el descubrimiento de los métodos de datación y análisis. Lo que seguramente no podrían haber imaginado es que, pese a todos sus logros, la arqueología de fin de siglo esté siendo cuestionada, tanto por su objeto de estudio como por su legitimidad para investigarlo. De todos los desafíos que ha debido enfrentar la arqueología como disciplina científica y académica, los reclamos indígenas no son precisamente un reto de menor importancia.

Consolidado el proceso de descolonización y reconocidos casi universalmente los derechos humanos básicos, las minorías étnicas y religiosas hallaron un contexto internacional y/o nacional propicio para hacer oír sus reclamos sobre las tierras 
que tradicionalmente ocuparon. El paulatino reconocimiento de esos derechos y el afianzamiento de su identidad étnica ha dado origen a un proceso de recuperación de sus tradiciones y valores espirituales, que involucra también los restos humanos de sus antepasados y elementos que integran el patrimonio cultural. Es allí cuando surge la disputa con los arqueólogos y antropólogos físicos por lo que parecía ser un patrimonio indiscutible para la ciencia.

Desde el siglo pasado la arqueología y los museos nacionales jugaron un papel importante en la consolidación de los nuevos Estados nacionales (Kohl y Fawcett, 1995). El territorio y la cultura material que se hallaban en éllos eran considerados elementos unificadores y claves para la formación de las tradiciones nacionales (Hobsbawm y Ranger, 1983). Así surgió la idea de un patrimonio cultural único, indisputable y compartido por todos los miembros de esa nación que debía estar en manos de dos grandes custodios: el Estado, quien lo protegería a través de la legislación, los museos y demás organismos administrativos y la ciencia, cuya investigación contribuiría a engrandecer el pasado nacional.

En los últimos años, Estado y ciencia han sido cuestionados en su legitimidad para manipular y disponer bienes reclamados por las comunidades indígenas como propios. Una amplia variedad de ítems que van desde restos humanos de todo tipo (huesos, cuerpos momificados, pelos, etc.), objetos funerarios asociados, religiosos y/o sagrados, hasta el patrimonio cultural de una comunidad, tribu, etc. han sido objeto de reclamos. Es necesario distinguir las demandas efectuadas por comunidades nativas a las instituciones de los países donde están establecidas o a terceras naciones, principalmente europeas que fueron sus ex metrópolis, de los reclamos sobre restitución de bienes culturales objetos de tráfico ilegal o apropiación ilegal durante conflicto armados, así como de la restitución solicitada por las naciones de origen a países europeos que llevaron a cabo importantes excavaciones arqueológicas y exportación de piezas (e.g. mármoles del Partenón Grecia, los bronces de Benin por parte de Nigeria, etc.). En este sentido, Moira Simpson (1995) distingue entre restitución y repatriación. Mientras que se emplea el término "restitución" cuando se trate de objetos robados o apropiados ilícitamente en contravención con las leyes internacionales y las convenciones de la UNESCO de 1954 y 1970 , se reserva el término "repatriación" para aquellos ítems que son poseídos legalmente de acuerdo a las nor- mas internacionales, pero que son reclamados por sus propietarios tradicionales o sus descendientes, desafiando las normas nacionales y las políticas de los museos, quienes sostienen la legalidad de sus derechos sobre las colecciones (Simpson, 1995: 5).

El término repatriación además se basa en la idea de devolver a los pueblos o comunidades originarias aquello de lo que han sido despojadas por las potencias coloniales o los Estado nacionales. Otro término utilizado para describir los reclamos en relación a los restos humanos indígenas es el de reinhumación, aludiendo al destino que se les va a dar a los restos humanos una vez recuperados.

En este trabajo se analiza la evolución de la denominada cuestión de las reinhumaciones (reburial issue) en distintos países, con especial énfasis en Latinoamérica y se discuten las implicancias legales, profesionales y éticas de la misma para la arqueología y la gestión del patrimonio cultural.

\section{CIENCIA VERSUS SACRALIDAD: EL DESARROLLO DE LA CUESTIÓN DE LAS REINHUMACIONES}

La mayor parte de las colecciones de restos humanos indígenas de diferentes partes del mundo que se hallan en los museos fueron colectadas en el siglo pasado. De acuerdo con las teorías darwinianas en boga, se asumía que las poblaciones nativas constituían una suerte de "salvajes contemporáneos" que estaban estrechamente relacionados en cuanto a comportamiento cultural, capacidad mental, tamaño de la masa encefálica y estructura craneana con los ancestros del Homo sapiens y que como aquel éstos también estarían prontos a extinguirse (Stocking, 1988: 8). Aún cuando a mediados de este siglo las colecciones de restos humanos cayeron en desuso, siguieron siendo una parte importante de las colecciones de museos e instituciones académicas y hasta han sido consideradas una parte indiscutible del patrimonio nacional.

La excavación arqueológica de enterratorios y tumbas no ha sido cuestionada sino hasta dos décadas atrás cuando comienza a gestarse, casi al mismo tiempo en Estados Unidos de América y en Australia, el denominado reburial issue. Desde entonces movimientos indigenistas han comenzado a disputar la propiedad y el control sobre los restos humanos de sus ancestros que se encuentran en museos o están sepultados en sitios arqueológicos. Los primeros registros de reclamos datan de

T. P., 57, n. ${ }^{\circ} 1,2000$ 
comienzos de los años setenta, cuando un grupo de nativos americanos agrupados bajo la denominación de American Indians Against Desecration (AIAD) comenzaron a exigir la reinhumación de restos de sus antepasados, al tiempo que los aborígenes australianos centraron sus reclamos en la oposición a la excavación de tumbas (Hubert, 1992: 107-108). En 1986 el conflicto de intereses entre organizaciones indígenas e investigadores se discutió por primera vez en una reunión internacional: el primer Congreso Mundial deArqueología realizado en Southampton, Inglaterra.

Paradójicamente los restos humanos que fueron poco estudiados por décadas adquieren una insospechada importancia como base de datos científica desde que comenzaron a efectuarse estudios de $\mathrm{ADN}$ en restos óseos antiguos. Actualmente la disputa entre pueblos indígenas e investigadores está lejos de ser resuelta y se ha extendido a restos humanos hallados en sitios muy tempranos (e.g. los entierros de Kow Swamp's enAustralia, Mulvaney, 1991; el hombre de Kennewick en Estados Unidos, verV), así como a pelo humano encontrado en contextos arqueológicos (Morell, 1995: 1425).

Diferentes grupos étnicos de otras partes del mundo han también comenzado a reclamar los restos de sus ancestros (e.g. grupos indígenas en Sudamérica, Inuits de Escandinavia, Judíos Ortodoxos en Israel, etc.)(Hubert, 1989: 157-161; también Jones y Harris, 1998). La disputa debe ser entendida como un conflicto entre dos diferentes sistemas de creencias (Hubert, 1992: 107). Mientras los pueblos indígenas reclaman el control sobre su patrimonio cultural como una cuestión de derechos humanos básicos (Langford, 1983), los investigadores alegan que ésto es una pérdida del patrimonio de toda la humanidad, el cual es también la base de datos para el desarrollo de la arqueología y la antropología física (Morell, 1995; Mulvaney, 1991). Sin embargo, los argumentos científicos contra la reinhumación no parecen ser suficientes para evitar el reconocimiento de un derecho demandado por las minorías étnicas como un medio necesario para recobrar su propio pasado, identidad y dignidad (Chippindale, 1991: 759). Algunos investigadores han alentado a sus colegas a evaluar las implicaciones éticas y filosóficas concernientes con el estudio de restos humanos con el objeto de tratar de comprender la visión de los pueblos indígenas y abrir un diálogo con ellos (Bahn, 1984; Zimmerman, 1987, 1989a, b; Creamer, 1990; Bowdler, 1992; McManamon, 1995).

\section{DERECHOS HUMANOS Y LÍMITES ÉTICOS}

En las últimas décadas estos reclamos comenzaron a ser paulatinamente reconocidos en convenciones internacionales, en algunas legislaciones nacionales, así como en códigos de ética profesional y políticas internas de museos. ElAcuerdo de Vermillion sobre restos humanos celebrado durante el WAC Inter-Congress de 1989 en South Dakota (ver WorldArchaeological Bulletin, 1989) dió por resultado el primer código de ética sobre esta temática que fue aprobado en el Segundo Congreso Mundial de Arqueología, efectuado en Barquisimeto, Venezuela en 1990. En el mismo se reconoce "la especial importancia que los restos humanos de los ancestros indígenas y los sitios que contienen dichos restos tienen para los pueblos indígenas"(arts. 2 y 3). Asimismo'se afirma que "el patrimonio cultural indígena pertenece legítimamente a sus descendientes, quienes tienen sus propias metodologías para interpretarlo, administrarlo y protegerlo, al tiempo que reconoce la necesidad de establecer una relación y participación equitativa entre investigadores y pueblos indígenas cuya herencia cultural está siendo investigada (arts. 5, 6 y 7)(ver World Archaeological Bulletin, 1991).

El reconocimiento de los derechos de los pueblos nativos en el mundo ha requerido un lento proceso de aceptación. En la actualidad el derecho a su patrimonio cultural es incorporado, a través del derecho de los indígenas a su cultura, como un derecho humano básico (e.g. Conferencia Mundial de Derechos Humanos, Viena, 1993). En los últimos años, Naciones Unidas ha dedicado especial atención a los problemas de los pueblos indígenas. Ejemplo de ello lo constituyen la "Convención sobre Tribus y Pueblos Indígenas en Países Independientes" adoptada por la Organización Internacional del Trabajo, la "Declaración sobre los Derechos de las Personas que pertenecen a Minorías Nacionales, Étnicas, Religiosas o Lingüísticas", así como la decisión de la Asamblea General de la ONU de declarar el período 1995-2004 como la "década internacional de los pueblos indígenas del mundo", con el propósito de llamar la atención de todos los estados, del sistema de las Naciones Unidas y de las organizaciones no gubernamentales para que contribuyan a mejorar las condiciones diarias de vida de estos pueblos.

Uno de los logros más significativos en materia de patrimonio cultural indígena es la elabora- 
ción de un Proyecto de Declaración de las Naciones Unidas sobre Derechos de los Pueblos Indígenas aprobado por la Subcomisión sobre Prevención contra la Discriminación y Protección de Minorías en 1994 y sometido a la consideración de la Comisión de Derechos Humanos en 1995. Aún cuando el texto está en proceso de revisión, se deduce una clara política sobre patrimonio cultural indígena y repatriación de restos humanos. En dicho proyecto se establece que: "Los pueblos indígenas tienen el derecho a (...) mantener, proteger y desarrollar las manifestaciones pasadas, presentes y futuras de sus culturas, tales como sitios arqueológicos e históricos, artefactos, ceremonias (...) tanto como los derechos a la restitución de propiedad cultural, intelectual, religiosa y espiritual tomada sin el libre e informal consentimiento o en violación a sus leyes, tradiciones o costumbres" (art. 12).

Asimismo se declara que, "Los pueblos indígenas tiene el derecho a manifestar, practicar, desarrollar y enseñar sus tradiciones espirituales y religiosas, costumbres y ceremonias; el derecho a mantener, proteger y tener acceso en privado a sus sitios culturales y religiosos y el derecho a usar y controlar sus objetos ceremoniales, así como el derecho a la repatriación de restos humanos. Los estados deberán tomar medidas efectivas junto con los pueblos indígenas involucrados para asegurar que los lugares sagrados indígenas, incluidos los sitios cementerios, sean preservados, respetados y protegidos" (art. 13) (Galla, 1997: 144-145).

Algunos países han implementado políticas que permiten a los aborígenes participar en la gestión y control de dicho patrimonio (e.g. Australia, Canadá y Estados Unidos). En 1990 el gobierno federal de Estados Unidos dio un paso trascendental en materia de repatriación, al aprobar la ley conocida como The Native American Grave Protection and Repatriation Act (NAGPRA). Esta norma tiene por objetivo proteger las tumbas indígenas en tierras federales y tribales, otorgándole a las tribus el control sobre el tratamiento de las tumbas aún no identificadas, al tiempo que prohibe la venta comercial de esqueletos nativos. Asimismo exige el inventario y la repatriación de los restos humanos que se encuentren en manos del gobierno federal o instituciones que reciban fondos federales, así como la devolución de los objetos funerarios o sagrados robados o impropiamente adquiridos y otras propiedades comunales significativas que sean reclamados por sus dueños tradicionales (Echo-Hawk y Echo-Hawk, 1994: 38).
La ley admite la repatriación de los ítems culturales si se prueba la existencia de un descendiente en línea directa de su poseedor. De lo contrario podrá acreditarse, demostrando que el bien era propiedad o estaba controlado por la tribu o por alguno de sus miembros. Uno de los aspectos más novedosos de esta norma es la flexibilidad de la prueba de la filiación cultural que puede ser probada sobre la base de "información geográfica, de parentesco, biológica, arqueológica, antropológica, lingüística, folklórica, tradición oral, histórica, así como toda otra información relevante u opinión experta" (Sec.7 a-4). Esta prueba consiste en una evaluación general de la totalidad de las circunstancias, sin necesidad de alcanzar certeza científica (Trope y Echo-Hawk, 1992). Se admiten dos excepciones a la repatriación. La primera consiste en la acreditación, por parte de los museos, de su derecho de posesíón sobre los objetos reclamados (e.g. adquiridos por cesión voluntaria). La segunda, se refiere a los ítems culturales que están siendo objeto de estudios científicos. En este caso, se establece que su devolución deberá hacerse efectiva dentro de los noventa días de haberse completado dichos estudios (Sec. 7 b).

Como consecuencia de esta ley, investigadores, organismos gubernamentales y empresarios privadas están obligados a convenir con las tribus las tareas que planean realizar cuando se pudieran afectar bienes del patrimonio cultural aborigen. Ejemplo de ello es el memorándum de entendimiento para proteger los restos humanos de nativo-americanos y objetos asociados que pudieran ser descubiertos con motivo de la construcción de un gasoducto, celebrado en Arizona en 1991, entre la Transwestern Pipeline Company, la Nación Navajo, las Tribus Hopi, Zuni, Yavapai-Prescott y el Forest Service, Southwestern Region y el Bureau of Land Management, Arizona State, en representación del gobierno federal y estatal respectivamente.

La aplicación de esta ley ha resultado conflictiva para las partes involucradas y ha generado desconfianzas mutuas. Los representantes de los museos se preguntan cómo van las tribus a conservar y proteger los objetos que son devueltos (Campbell, 1994). Por su parte las comunidades aborígenes afirman que «los museos no son instituciones nuestras. Nuestra relación con los objetos y los restos humanos es diferente: todos y todas las cosas existen en un sistema de relaciones. Somos parte de un mundo orgánico en el cual las interrelaciones en

T. P., 57, n. ${ }^{\circ} 1,2000$ 
todos los niveles de vida son honorables» (Naranjo, 1994).Arqueólogos, antropólogos, museólogos $\mathrm{y}$ administradores de recursos culturales se han vistos obligados, por esta ley, a respetar los derechos indígenas, aún aquellos relativos a cuestiones sagradas o religiosas. Este difícil proceso es comparado por Alston Thoms (1994: 1) con el vivido por los americanos blancos, luego de la aprobación de las leyes de derechos civiles de los afroamericanos en Estados Unidos.

Después de varios años de aplicación esta ley ha hecho posible la repatriación de cientos de restos humanos lo cual ha generado un fuerte debate así como una profunda crisis entre arqueólogos, antropólogos físicos, curadores y administradores de recursos culturales, quienes deben enfrentar el desafío de negociar con las comunidades aborígenes los términos de su trabajo profesional.

En Australia, el gobierno ha promovido una política a favor de los reclamos indígenas a través de diferentes normas jurídicas (e.g. the Federal Aboriginal andTorres Strait Islander Heritage Protection Act de 1984) y ha apoyado la repatriación de restos humanos e ítems del patrimonio cultural a las comunidades aborígenes no sólo dentro del país sino también en el exterior, sobre todo en Reino Unido (1) (Flood, 1989). Pese a estos avances, la política australiana ha sido criticada recientemente porque no ha sido capaz de proveer mecanismos legislativos que faciliten el retorno y garanticen el control de las comunidades aborígenes sobre su propiedad cultural (Ormond Parker, 1997: 11).

La repatriación de los restos humanos aborígenes a sus descendientes actuales, así como los objetos sagrados o religiosos a las comunidades de origen, es un derecho cuyo reconocimiento genera resistencia en las autoridades, así como en los museos e instituciones que han almacenado dichos bienes durante décadas. Sin embargo, desde el ámbito académico se ha cuestionado la posesión de los mismos, y en especial el tratamiento ético de los restos humanos (Creamer, 1990; Hubert, 1989, 1992; Webb, 1987; Zimmerman, 1989a y b).

Asimismo asociaciones profesionales de museos comenzaron a considerar en sus estándares éticos a los restos humanos y a los objetos sagrados como "materiales sensibles" que merecen un trato cuidadoso y respetuoso siguiendo el criterio adoptado

(1) Ver C. Fforde: Controlling the Dead: An Analysis of the Collecting and Repatriation of Aboriginal Human Remains. Tesis doctoral inédita. University of Southampton. Reino Unido, 1997: 134. por el Código de Etica Profesional de ICOM de 1986 (e.g. UK Museum Association Code of Conduct for Museum Professionals de 1997), así como a reconocer el genuino interés de las comunidades indígenas respecto de los restos de sus antepasados (e.g. American Association of Museums; Canadian Museum Association; Society of Professional Archaeologists Guidelines, Gran Bretaña, de 1991; Australian Archaeological Association Code de 1991).

Algunos museos han cambiado sus políticas y han comenzado a sacar de sus exhibiciones a los restos humanos, así como a brindar información acerca de sus colecciones (e.g. el Museo Pitt Rivers en Oxford, Reino Unido). Otras instituciones han marcado verdaderos hitos accediendo voluntariamente a la devolución de restos humanos. Así por ejemplo, the Australian Institute of Aboriginal Studies accedió a devolver en 1976 un esqueleto encontrado en un garaje en Melbourne (Hubert, 1989, 154). Políticas similares fueron adoptadas en 1990 por la Universidad de Cambridge (2) en Inglaterra y en 1991 por The Smithsonian Institution de Estados Unidos (e.g. repatriación de Larsen Bay en 1991, Bray y Killon, 1994).

Al contrario de lo que ocurre en Australia, Canadá y EEUU, no existe en los países europeos políticas de repatriación de alcance nacional, por lo que debe analizarse la política de cada museo en particular. Sólo algunos museos europeos han accedido a los reclamos de repatriación efectuado por países no europeos (e.g. el Musée Royale de L'Afrique Centrale de Bélgica devolvió a Zaire una colección etnográfica procedente del este de dicho país; el $\mathrm{Na}$ tionalmuseum de Suecia retornó a Guatemala una estela maya al comprobar que había sido obtenida ilegalmente, Simpson, 1997: 61-62). Sin embargo, hay un gran número de museos e instituciones académicas que rehusan proveer información sobre sus colecciones no sólo a las organizaciones indígenas sino también a investigadores en general (Ucko, 1992, 1-2; Simpson, 1994; Southworth, 1994).

\section{REINHUMACIONES EN ESPAÑA}

En España la cuestión de las reinhumaciones no ha tenido aún un impacto significativo a nivel na-

(2) Ver C. Fforde: Controlling the Dead: An Analysis of the Collecting and Repatriation of Aboriginal Human Remains. Tesis doctoral inédita. University of Southampton. Reino Unido, 1997: 138 .

T. P., 57, n. $^{\circ} 1,2000$ 
cional, aunque los pocos casos que se presentaron tuvieron una repercusión inusitada en la prensa local y nacional, llegando incluso a los estrados judiciales u originando conflictos diplomáticos, lo cual permite predecir el conflicto potencial que el tema puede alcanzar a una escala mayor. A manera de ejemplo se detallan dos casos particularmente paradigmáticos, que a pesar de haber llegado, hasta el momento, a resultados divergentes, presentan características comunes.

El primero es el del denominado "negro de Banyoles", un bosquimano que fue desenterrado en 1830, disecado y conducido a Francia por naturalistas franceses. En 1916 el negro llegó a Banyoles como parte de las colecciones que Francesc Dardes donó a la ciudad y que constituyeron el museo que lleva su nombre. Desde entonces su cadáver embalsamado permaneció exhibido en una vitrina. En 1992, la polémica fue iniciada por el médicoAlfonso Arcelín quien solicitó "dignificar al hombre disecado, pidiendo que sea devuelto a su lugar de origen probablemente Botswana- para ser enterrado o incinerado tras una ceremonia de desagravio". La resistencia de los vecinos de Banyoles, que pudo en principio considerarse como una cuestión de escaso alcance local, tomó características de conflicto diplomático entre España y los países de la Organización para la Unidad Africana. A ello se sumó la Asociación de Museólogos de Cataluña que consideraron que el bosquimano tenía "gran valor patrimonial y museístico" por lo cual debería conservárselo. Finalmente la intervención de la UNESCO, aconsejando la inhumación o el traslado del bosquimano a su país de origen y la reper-cusión insospechada del reclamo, motivó un cambio de actitud del alcalde de Banyoles quien retiró primero al guerrero de la exhibición y propuso luego la incineración de su cuerpo (ver Jaume et alii, 1993; Diario El País, Madrid, 06/03/95 y 31/03/97).

El segundo caso de análisis es el de la necrópolis de judíos del siglo XIV hallados en la calle Romagosa en Valencia, en 1996. En esta oportunidad, el Ayuntamiento de Valencia y la Consellería de Cultura decidieron hacer lugar al pedido de la Federación de Comunidades Israelitas de España autorizando el traslado de los cuerpos a un cementerio de Barcelona sin ser previamente analizados por los arqueólogos que efectuaron la excavación. La decisión motivó la reacción de la comunidad arqueológica que interpuso un recurso de queja ante el Defensor del Pueblo de las Cortes Valencianas, quien se expidió, en 1998, en contra de la re- solución adoptada por las autoridades locales, amparándose en que el cementerio es patrimonio arqueológico, por ende está protegido por la ley de patrimonio histórico español y argumentando que no se respetó el necesario equilibrio entre el respeto a la religión y la conservación del patrimonio.

Más allá de lo anecdótico, este caso ha servido para poner de manifiesto el conflicto de valores que el tema ha generado en este país. Mientras para el Conseller de Cultura de Valencia "los intereses arqueológicos van detrás del sentimiento religioso" (Diario Levante, Valencia, 29/04/98) y la comunidad judía de Valencia señala que ella "siempre ha defendido que no es lo mismo una vasija que un cuerpo" y que su solicitud se basó en el "derecho a que se respete el descanso que se dio a estos judíos cuando fueron enterrados en su tiempo" (Levante, 12/05/96), la Comisión de Arqueología del Colegio de Doctores y Licenciados en Filosofía, Letras y Ciencias afirmó que la reinhumación "sería lo mismo que sepultar un archivo de documentos tras haberlos leído" (Levante, 12/04/96). Finalmente el Síndic de Greuges en su resolución afirmó que la reinhumación mencionada significó "un total sacrificio del derecho a la cultura de los ciudadanos" y "la pérdida de una pieza de nuestra historia, sustrayendo del estudio científico una parte de nuestro patrimonio arqueológico, como parte de nuestro patrimonio cultural", concluyendo que "debieron ser estudiados con métodos arqueológicos para la mejor comprensión de nuestra historia", aunque su "valor sagrado" debería ser tenido en cuenta "a efectos de determinar el destino final de los restos una vez estudiados"(Levante, 29/04/98).

Estos dos casos reflejan con notable claridad la antinomia: objeto de estudio - sacralidad de los restos humanos, así como patrimonio nacional y/o de la comunidad local - derechos de una comunidad étnica o religiosa determinada. En ambos casos, además, el tema se planteó como un acto de desposesión a la comunidad local, ya que los restos en cuestión eran sacados del lugar donde se hallaban depositados.

\section{EL CASO DEL HOMBRE DE KENNEWICK (EE.UU.) Y EL PROBLEMA DE LOS RESTOS PALEO-AMERICANOS}

En 1996, cuando el derecho de repatriación de los pueblos nativos americanos parecía definitivamente consolidado en EEUU, un esqueleto hallado 
de manera casual en las márgenes del Río Columbia en Kennewick, Washington, dio lugar a una disputa sin precedentes entre los arqueólogos, las comunidades indígenas y la agencia federal a cargo del cumplimiento de la ley de repatriación (NAGPRA). El conflicto comenzó cuando el Cuerpo de Ingenieros del Ejército, propietario del terreno donde se efectuó el hallazgo, anunció su decisión de entregar el esqueleto a las tribus Umatilla para su reinhumación, sin permitir continuar los estudios, en cumplimiento con lo dispuesto por la ley.

Las razones de la polémica se debieron no sólo a la antigüedad de los restos (los fechados iniciales le asignan entre 8400 y 9300 años B.P. (Morell, 1998; Slayman, 1997) sino también a su aparente importancia. En efecto, de acuerdo con observaciones superficiales, los investigadores han señalado que por las características óseas del cráneo se asemejaría más a poblaciones de Europa o de Eurasia que a poblaciones recientes nativo-americanas (ver Chatter, 1997; Swedlund y Anderson, 1999).

Por otra parte, dada la profundidad temporal de los restos, es imposible probar la filiación cultural del hombre de Kennewick con las comunidades indígenas actuales, por lo que se recurre a una presunción legal: en tierras públicas, se le da prioridad de repatriación a aquella tribu que cuenta con un reclamo válido de tierras en el área. Por dicha razón las tribus confederadas de la Reservación Umatilla (Pendleton, Oregon) tienen el derecho de decidir sobre el destino de los restos, pese a no poder acreditar la filiación cultural con los mismos.

La reacción de los arqueólogos no se hizo esperar, numerosas cartas fueron enviadas al Cuerpo de Ingenieros del Ejército protestando por la decisión de no continuar los estudios. William Lipe, presidente de la Society for American Archaeology, en una carta dirigida al editor del periódico New York Times (Nueva York, 04/10/1996) solicitó a la tribu que reclamó el esqueleto que "reconsidere su posición y permita efectuar estudios adicionales" (ver Lipe, 1996: 4).

Por su parte, las tribus involucradas no dudan de su derecho a reclamar el esqueleto, ya que de acuerdo a su tradición oral, sus tribus fueron "parte de esta tierra desde el comienzo de los tiempos" y no creen que sus pueblos "hayan migrado desde otros continentes como lo consideran los científicos" (Morell, 1998: 192).

El denominado "Kennewick Man" no es un caso único desde el punto de vista de sus características morfológicas, sino que comparte rasgos similares con otros hallazgos de restos humanos de similar antigüedad tales como el "Spirit Cave Man" (9000 a 9500 B.P.) y el "Wizard Beach Man", encontrados en la Gran Cuenca al oeste de Nevada, EEUU. Estos restos presentan algunos elementos distintivos, "que no son encontrados en nativos americanos más tardíos del oeste de Estados Unidos, pero que podrían ser una combinación de rasgos recesivos de un ancestro común pre-racial de todos los humanos modernos y (constituir un) emergente Proto-Indio" (Dansie, 1999: 31).

El resultado de los estudios de estos restos pueden contribuir a generar nuevas hipótesis sobre el poblamiento de América, por lo que la obligación legal de devolverlos ha sido comentada con dramatismo: "Irónicamente estas ventanas hacia el pasado humano se han abierto justo cuando los restos que podrían dar las respuestas están siendo reclamados para su repatriación en todo el mundo" (Dansie, 1999: 31).

La entrega del esqueleto por parte de los investigadores para que quede bajo custodia federal y la cobertura del sitio donde se produjo el hallazgo con varias toneladas de tierra "para protegerlo de la erosión" (ver Morell, 1998: 192) parecía poner fin a las expectativas de su estudio. Sin embargo, en la causa judicial iniciada por los científicos se ha compelido al Cuerpo de Ingenieros del Ejército -y éstos a la agencia federal encargada de ejecutar la ley-a "examinar críticamente la evidencia en el registro como un todo", para saber si el hombre de Kennewick "es un nativo americano". Mientras se aguardan los resultados de nuevos fechados radiocarbónicos solicitados por la agencia federal para responder a la justicia quien tiene derecho sobre los mismos, el representante legal de los científicos critica la premura con que ha actuado el gobierno para dar por terminado el pleito y los grupos indígenas se oponen enfáticamente a la realización de dichos estudios, ya que la destrucción de los huesos utilizados para los fechados constituye una "ofensa religiosa" (nota publicada por el periódico local Tri-City Herald, 03/11/99; http://www.tricityherald.com/bones/news).

Mientras unos y otros luchan por el control del pasado, las expectativas en torno a la posible existencia de un ancestro de características "caucásicas" en América ha atraído la atención de los medios de prensa, quienes no dudaron en ofrecer un espacio alternativo para librar la batalla. La reconstrucción del rostro del hombre de Kennewick es mostrada con todo detalle en videos preparados para la tele- 
visión, al tiempo que las noticias periodísticas pueden ser seguidas día a día por el público a través de internet (e.g. Kennewick Man Virtual Interpretative Center: http://www.tri-cityherald.com/bones).

\section{LA SITUACIÓN EN LATINOAMÉRICA}

EnAmérica Latina el reconocimiento de los derechos de los indígenas a su patrimonio cultural, al igual que otras reivindicaciones indígenas, se vieron frustrados por los gobiernos autoritarios. Recién en la década de los ochenta, con el advenimiento de la democracia, los países latinoamericanos comenzaron un lento proceso de aceptación de sus reclamos (López Mazz, 1990; Podgorny y Politis, 1992; Politis, 1992, 1995; Vasco Uribe, 1990). Los esfuerzos de las comunidades y organizaciones indígenas latinoamericanas están principalmente abocados a modificar las legislaciones nacionales para obtener reconocimiento jurídico y la propiedad de las tierras que tradicionalmente ocupan, así como satisfacer sus necesidades más elementales de vida. No obstante, distintas acciones de recuperación de su patrimonio cultural están siendo promovidas por comunidades o agrupaciones indígenas con el objeto de tener un contacto más directo y un mayor control sobre sus propios bienes culturales. Así por ejemplo, se ha promovido la idea de crear museos comunitarios (e.g. la comunidad de Agua Blanca en el Parque Nacional Machalilla en Ecuador, ver McEwan et alii, 1994), la custodia de sitios cementerios por parte de la comunidad (e.g. museo de sitio deAñelo, en Neuquén, Argentina), la recuperación de bienes que han sido objeto de saqueo y comercialización (e.g. textiles precolombinos de Coroma, Oruro, Bolivia) o la realización de investigaciones arqueológicas con el fin de mejorar el conocimiento de su propio pasado (e.g. apoyo de la Comunidad India Quilmes al ProyectoArqueológico en la ciudad de Quilmes, Buenos Aires, Argentina, ver Quatrin de Rodríguez, 1999). En todos estos casos las acciones de recuperación se efectúan con la colaboración y el esfuerzo mancomunado de arqueólogos y comunidades.

Sin embargo, existen también casos conflictivos que han motivaron incluso la iniciación de causas judiciales. Así por ejemplo, en 1992 los indios papago (tohono odham) lograron que por decisión judicial, el Instituto Nacional de Antropología e Historia (INAH) de México devolviera los entierros de sus ancestros excavados por una misión france- sa en Quitobac, Sonora (Vázquez León, 1996: 9899). En 1999 la Comunidad Kolla denunció judicialmente la violación de los derechos de su pueblo a raíz del hallazgo y excavación de tres momias incaicas encontradas en el volcán Llullaillaco, en Salta, Argentina (ver Reinhard, 1999). La denuncia se fundó en que se trataba de un sitio sagrado de huacas de alturas, ubicado en territorio indígena perteneciente a vigencia viva del Tawantinsuyo, que las personas encontradas eran miembros del pueblo indígena del Kollasuyo, Llullaillaco y que se ignoró la consulta a un pueblo indígena vivo. Sin embargo, la denuncia fue desestimada por el Fiscal Federal porque la expedición arqueológica que las había hallado había sido legalmente autorizada.

Estos dos casos tienen por denominador común el hecho de que tenían por objeto restos humanos indígenas, aunque el resultado de la resolución ha sido diferente en cada uno de ellos, reconociéndose en él primer caso e ignorándose en el segundo, la continuidad de los pueblos y la existencia de las tradiciones culturales vivientes.

EnArgentina, con motivo de los hallazgos de las momias del Llullaillaco, de los reclamos indígenas y de la amplia repercusión que todo el caso tuvo en la prensa nacional e internacional, la Universidad Nacional de Salta (CEPIHA, Facultad de Humanidades) convocó en noviembre de 1999 a una mesa redonda a efectos de discutir las implicancias éticas de este tipo de hallazgos con la presencia de representantes indígenas. Como conclusiones de dicha reunión se recomendó contemplar en la legislación y en los códigos de ética profesionales los derechos e intereses de los pueblos indígenas en relación a su patrimonio cultural.

Por su parte, el nuevo Código de Etica adoptado por la Sociedad de Arqueología Brasileña en 1995, es pionero en la región, al reconocer como "legítimos los derechos de los grupos étnicos investigados a la herencia cultural de sus antepasados, a sus objetos funerarios, así como atender a sus reivindicaciones" (ap. 221), pese a que no se incluyó la propuesta original acerca de "restringir las intervenciones arqueológicas en sitios cementerios especialmente en los de grupos étnicos con descendencia conocida" (Andrada Lima, 1995-96: 610).

\section{EL VALOR DE LOS CASOS LÍDERES}

La triste historia del cacique "charrúa" Vaimaca Pirú y su retorno ha sido un tema largamente discu-

T. P., 57, n. ${ }^{\circ} 1,2000$ 
tido en Uruguay, incluso en debate parlamentarios En los últimos años, descendientes indígenas agrupados en I.N.D.I.A. (Integrador Nacional de Descendientes de Indígenas Americanos) han efectuado una basta campaña a nivel nacional e internacional para obtener la devolución de los restos de este "charrúa" que se encuentran depositados en el Musée de L'Homme de París, con el objeto de que sean inhumados en el Panteón Nacional. Este caso, que ha alcanzado notoriedad en la prensa nacional e internacional y hasta generado reacciones políticas y diplomáticas, marcó el comienzo de este debate en Uruguay.

Vaimaca Pirú fue capturado junto con cuatro indígenas más -entre ellos una mujer embarazaday llevado a Francia por un comerciante francés François De Curel en 1833. Allí fueron exhibidos en un espectáculo público como salvajes. La pro- testa del público dió origen a una decisión judicial que obligó a la liberación de los indígenas. Para entonces Vaimaca Pirú había muerto y su cuerpo habría sido llevado al Musée de L'Homme (Martínez Barbosa, 1996). En enero de 1999 este reclamo recibió el apoyo del World Archaeological Congress reunido en Ciudad del Cabo, Sudáfrica. Un mes después el periódico La República (Montevideo, 13/02/99) publicó una nota titulada: "El Museo del Hombre niega la extradición del último Charrúa", en la que se da cuenta de las gestiones infructuosas efectuadas por el embajador uruguayo en Francia. Conforme a esta fuente, el argumento esgrimido por el Museo se fundó en que "los restos del cacique poseen un gran valor antropológico como parte del patrimonio histórico del planeta, y que deben ser conservados en un lugar adecuado".

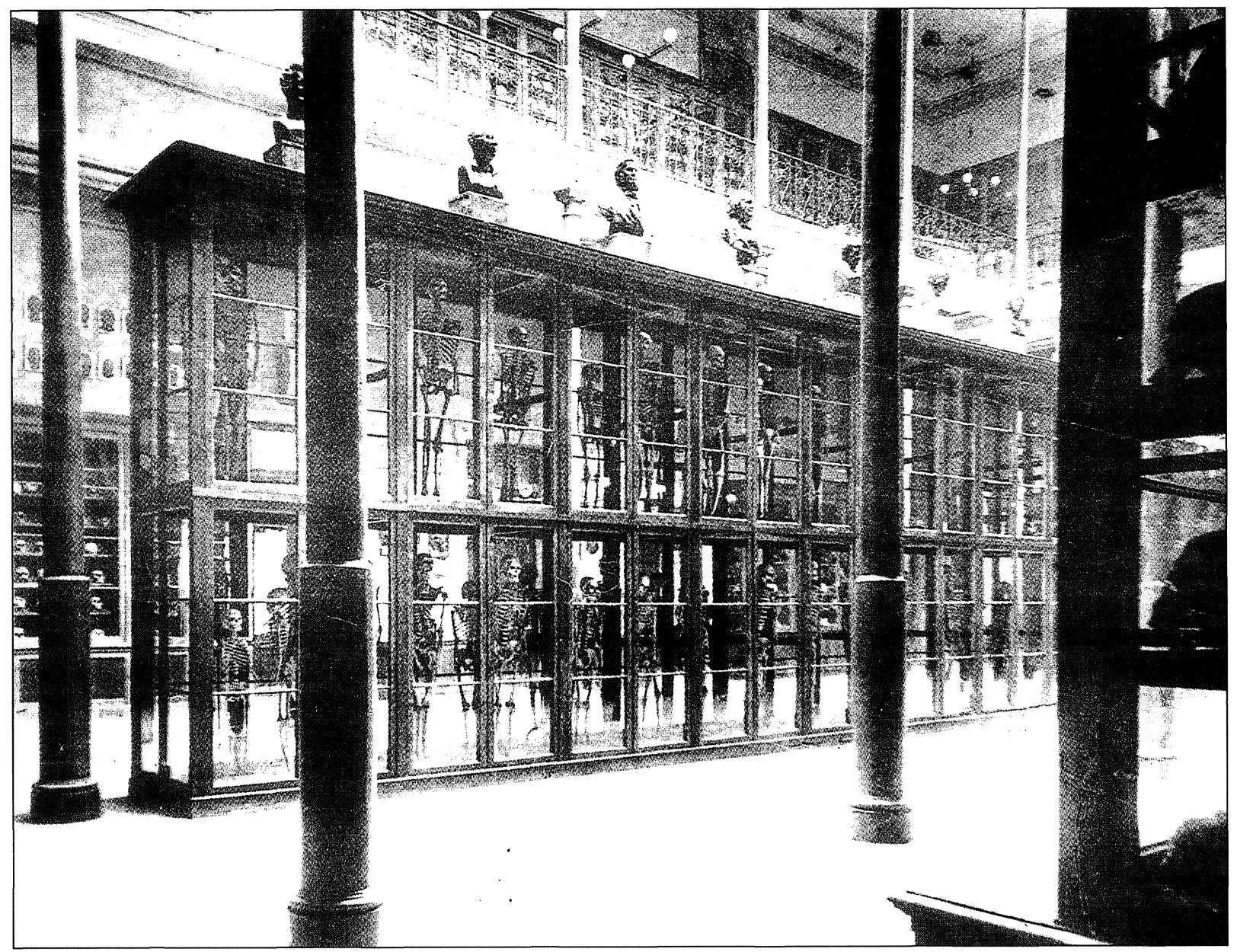

Lám. I. Vista de los esqueletos Mapuches y Tehuelches expuestos en la Sala I, Sección Antropológica del Museo de La Plata en 1891 entre los cuales se hallaban los restos de caciques que lucharon contra la Conquista del Desierto (foto publicada en la Revista del Museo, I (1890-91), lám. VII. Gentileza Dra. Irina Podgorny). 
En Argentina, se ha operado un importante cambio de actitud frente al tratamiento ético de los restos humanos, ya que por primera vez hubo una respuesta institucional favorablemente a un reclamo de una comunidad aborigen. Se trata de la restitución de los restos del cacique Inakayal efectuada en 1994.

El Museo de La Plata, dependiente de la Universidad Nacional de La Plata, alberga desde fines del siglo pasado una colección de esqueletos indígenas de la Patagonia y La Pampa (fundamentalmente tehuelches y araucanos), que perecieron o fueron tomados prisioneros durante la conquista de sus territorios a fines del siglo pasado (Lám. I). Estos esqueletos sobre todo los restos de caciques de conocida trayectoria histórica tales como Callfulcurá, Inakayal, Mariano Rosas, Manuel Guerra, Gherenal, Indio Brujo y Chipitruz- han sido objeto de reclamos por diferentes agrupaciones indígenas, así como por pobladores locales sin ancestros aborígenes, desde los años setenta. La Universidad de La Plata siempre se expidió en forma negativa, fundándose en que dichos restos eran bienes del dominio público del Estado o debido a la imposibilidad de probar legalmente el parentesco por consanguinidad (Podgorny, 1991; Podgorny y Miotti 1994; Podgorny y Politis, 1992). Igual suerte corrió el reclamo de la restitución del cráneo del cacique Cipriano Catriel, efectuado ante el Museo de la Patagonia Francisco Moreno (3). El único caso de restitución exitoso en Argentina fue el del cacique Inakayal, cuyo traslado a Tecka, provincia de Chubut fue aprobado mediante la ley 23.940/91, a iniciativa del Senador Solari Irigoyen. Notificado de la sanción de dicha ley, el Consejo Superior de la Universidad de La Plata, de quien depende el Museo de La Plata, volvió a tratar la devolución de Inakayal, decidiendo por unanimidad en esta oportunidad, acceder al reclamo (Miotti, 1994; Politis, 1994). En 1994, los restos del cacique Inakayal fueron entregados por las autoridades del Museo a la comunidad Mapuche-Tehuelche para ser enterrados en el valle de Tecka de donde era oriundo (Lám. II ). De este modo, se concretó en dicho país el primer caso de devolución de restos humanos a partir del reclamo de un grupo indígena, constituyendo un importante precedente para toda América Latina.

(3) Ver M. ${ }^{a}$ L. Endere: Collections of Indigenous Human Remains in Argentina: The Issue of Claiming a National Heritage. Tesis de Maestría inédita. Institute of Archaeology, University College London. Reino Unido, 1998.
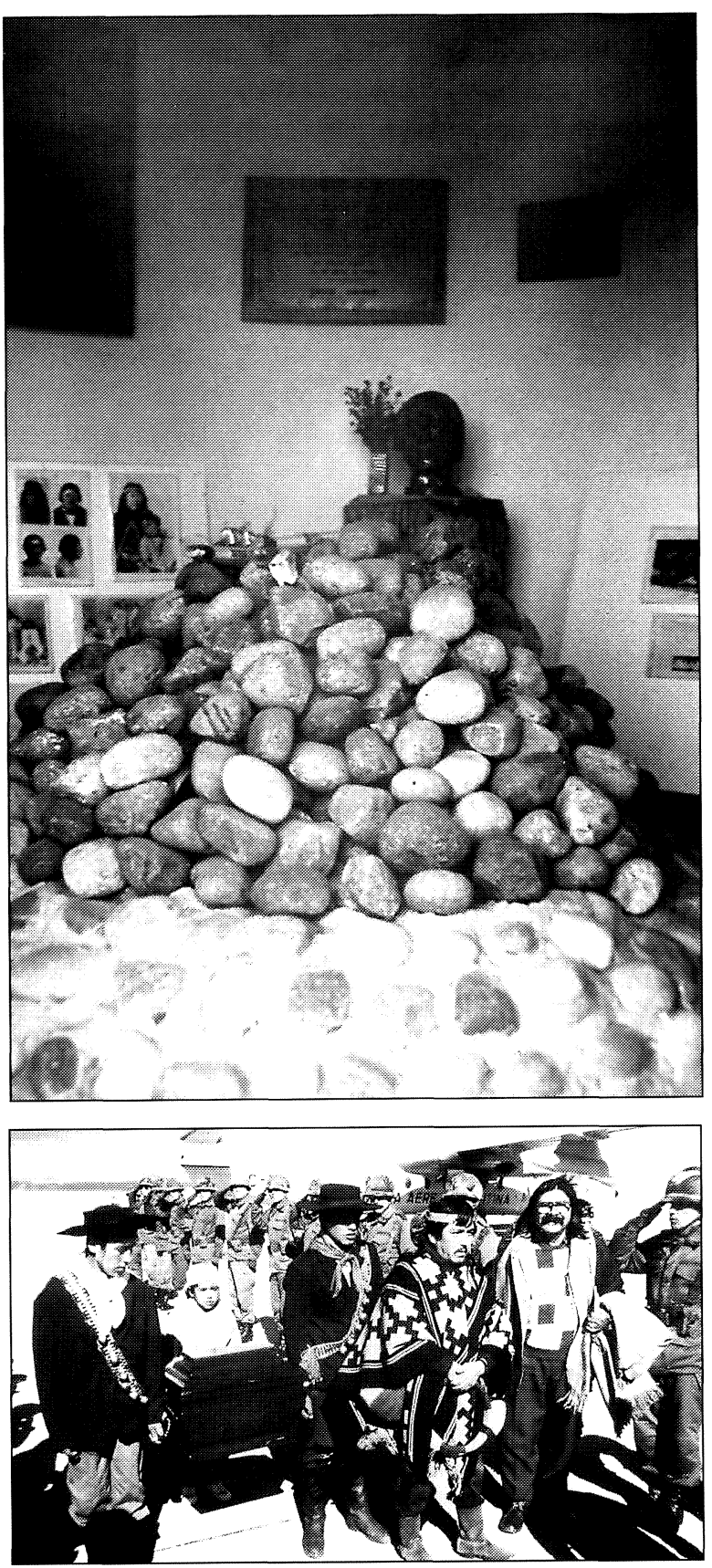

Lám. II. Arriba: Tumba del cacique Inakayal en su mausoleo de Tecka (Chubut, Argentina). Abajo: Los restos del cacique Inakayal, a su llegada al aeropuerto de Esquel (Chubut, Argentina), son conducidos por descendientes Mapuches, mientras reciben honores militares como héroe de la Nación (gentileza Dr. Gustavo Politis).

Todos los reclamos descritos en este apartado tienen la particularidad de tratarse de restos humanos de conocidos personajes de la historia y las 
solicitudes de devolución se fundaron en la necesidad de reivindicarlos como héroes nacionales y en algunos casos se prevé el depósito de sus restos en un monumento creado a tan efecto. Los reclamos de los caciques argentinos, además, suelen contar con el apoyo del gobierno municipal o provincial de donde eran oriundos, ya que de algún modo la devolución es percibida como la restitución de un patrimonio provincial. Por ello, el término "repatriación" no sería aplicable en estos casos, siendo más adecuado referirse a los mismo como reclamos de devolución de restos humanos (4).

\section{CONSIDERACIONES FINALES}

La mayoría de las generaciones presentes de arqueólogos hemos sido formados en un modelo de arqueología científica que presentaba una idea de pasado objetivado y separado de las tradiciones vivientes. Del mismo modo, los sitios y las colecciones arqueológicas que constituyen el patrimonio nacional eran considerados exclusivamente como cultura material sin tener en cuenta los significados sociales asociados a ellos y rechazando cualquier otra interpretación que no sea proveída desde el discurso arqueológico.

En reacción a ello, se ha enfatizado la necesidad de examinar el contexto social y político en el cual la arqueología se desarrolla (Trigger, 1984; Ucko, 1995 , etc.), así como admitir la existencia de otras visiones acerca del pasado. Ello ha obligado a la arqueología a "hacerse cargo" de cuestiones, tan susceptibles como conflictivas, como la repatriación y reinhumación de colecciones de restos humanos, la restitución de bienes culturales y el reconocimiento de la existencia de sitios y paisajes sagrados. De este modo, "los otros" recobran importancia en la discusión arqueológica (Layton, 1989a, b; Lowenthal, 1990; Preucer y Hodder, 1996, etc.) no como objetos de estudio como en la antropología tradicional, sino como un examen consciente de las propias implicaciones del trabajo arqueológico. En este sentido, uno de los mayores desafíos de la arqueología actual consiste en escuchar las voces de "los otros" con relación al patrimonio cultural.

El reconocimiento de derechos de los pueblos indígenas a su patrimonio cultural es una cuestión

(4) Ver M. ${ }^{a}$ L. Endere: Collections of Indigenous Human Remains in Argentina: The Issue of Claiming a National Heritage. Tesis de Maestría inédita. Institute of Archaeology, University College London. Reino Unido, 1998: 66-67. que requiere ser considerada en tres diferentes niveles: el legislativo, el profesional (arqueólogos, antropólogos físicos, curadores de museos, conservadores, etc.) y el de gestión del patrimonio. Sin embargo se observa que mientras se ha avanzado en la adopción de criterios a nivel internacional (e.g. ONU, Convenciones de la UNESCO, Código de ética de ICOM) existe cierta resistencia en la recepción de dichos criterios en las legislaciones y administraciones culturales nacionales salvo en los países que han liderado los cambios en la materia (e.g. Australia, Canadá y EEUU), así como en los códigos de ética de asociaciones profesionales y en las políticas de los museos en materia de repatriación.

Aún en países donde la repatriación parece ser un derecho definitivamente adquirido por las comunidades indígenas, situaciones como la planteada a raíz del hallazgo del Kennewick Man en EEUU, ponen de manifiesto no sólo la resistencia que genera el cumplimiento de la ley de repatriación, sino también la dificultad de establecer criterios legales capaces de compatibilizar los intereses científicos con los de las comunidades indígenas.

En Latinoamérica, la escasez de reclamos o su falta de éxito no puede ser explicada exclusivamente en término de impedimentos legales sino que deben buscarse las razones en el cúmulo de problemas que deben enfrentar las comunidades indígenas en esos países. A ello se suma su falta de conocimiento de la existencia de restos humanos de sus antepasados en museos nacionales y extranjeros, así como la carencia de catálogos de colecciones actualizados en muchos museos y la dificultad de acceder a dicha información.

No obstante, no debe subestimarse el poder simbólico de los primeros casos de devolución y el impacto que generan en el desarrollo de una política de repatriación, como han sido, por ejemplo, la reinhumación deTruganini, "la últimaTasmana" y el retorno de la colección Crowther, enAustralia, asî como la repatriación de Larsen Bay en Estados Unidos (Hubert, 1989; Bray y Killion, 1994). En este sentido, es necesario revalorizar la importancia del caso Inakayal en Argentina, los entierros de Quitobac en México, así como Vaimaca Pirú en Uruguay o el denominado "negro de Banyoles" en España.

La construcción del pasado desde una perspectiva pluralista exige conciliar los fines de la investigación científica con el respeto a los derechos humanos de las comunidades indígenas en relación a los restos humanos de sus antepasados y a su tradi- 
ción cultural. Una realidad desafiante nos espera a los arqueólogos en el nuevo siglo, para la cual la apertura, el diálogo y la negociación serán probablemente nuestras mejores herramientas metodológicas.

\section{AGRADECIMIENTOS}

A la Dras. Consuelo Mata (Dpto. de Prehistoria y Arqueología, Universidad de Valencia) y M. ${ }^{a}$ Isabel Martínez Navarrete por haberme facilitado material periodístico sobre reinhumaciones en España. A la Dra. Denise Arnold (Kings College, Londres) y a Rodolfo Martínez Barbosa por haberme proveído información sobre Bolivia y Uruguay respectivamente. A la Dra. Cressida Fforde (University College London) por permitirme citar su tesis doctoral inédita.

\section{BIBLIOGRAFÍA}

Andrada Lima, T. (1996): "Ética NaArqueologia Brasileira: Uma Proposta Complementar”. Coleção Arqueologia. EDIPUCRS, 1(1): 605-612.

BAHN, P. (1984): "Do not Disturb? Archaeology and the right of the Dead". Oxford Journal of Archaeology, 3(1): 127-130.

Bray, T. y KILLION, T. (eds.) (1994): Reckoning with the Dead. The Larsen Bay Repatriation and the Smithsonian Institution. Smithsonian Institution Press, Washington y Londres.

BowDLER, P. (1992): "Unquiet slumbers. The return of the Kow Swamp burials". Antiquity, 66: 103-106.

Campbell, M. (1994): "Introducción". En E.M. Campbell (comp.): Handbook of the NAGPRA Workshop (Texas, 1-2 noviembre 1994). Museum of Texas University/ National Park Service, Lubbock, Texas.

Chatters, J.(1997): "Encounter with an Ancestor". Anthropology Newsletter, 38(1): 9-10.

Chippindale, C. (1991): “Editorial”. Antiquity, 65: 759-60.

CREAMER, H. (1990): "Aboriginal perceptions of the past: implications for cultural resource management in Australia". En P. Gathercole y D. Lowenthal (eds.): The Politics of the Past. Unwin Hyman. Londres: 130-140.

DANSIE, A.(1999): "International Implications of the Impact of Repatriation in Nevada Museums". SAA Bulletin, 17(3): 30-32.

Eсно-HAwк, R. у Eсно-HАWк, W. (1994): Battlefields and Burial Grounds. The Indian Struggle to ProtectAncestral Graves in the United States. Lerner Publications. Minneapolis.

FLOOD, J. (1990): “Treat softly for you tread on my bones: the Development of Resource Management in Austra- lia". En H. Cleere (ed.): Archaeological Heritage Management in the Modern World. Unwin Hyman. Londres: $79-101$.

Galla, A. (1997): "Indigenous Peoples, Museums and Ethics". En G. Edson (ed.): Museum Ethics. Routledge. Londres: 142-155.

HoBSBAwm, E. y RANGER, T. (eds.) (1983): The Invention of Tradition. Cambridge University Press. Cambridge.

Hubert, J. (1989): “A Proper Place for the Dead: A Critical Review of the Reburial Issue". En R. Layton (ed.): Conflict in the Archaeology of the Living Traditions. Routledge. Londres: 133-166.

- (1992): "Dry Bones or Living Ancestors? Conflictive Perceptions of Life, Death and the Universe". International Journal of Cultural Property, 1: 105-127.

Jaume, D.; Pons, M; Palmer, M.; McMin, M.; Alcover, A. y Politis, G. (1993): "Racism, Archaeology and Museums: the strange case of the stuffed man from the Museu Darder, Banyoles (Catalonia)". WorldArchaeological Bulletin, 6: 113-118.

JONES, D. y HARRIS, J. (1998): "Archaeological Human Remains. Scientific, cultural and ethical considerations". Current Anthropology, 39: 253-264.

Kohl, P. y Fawcett, C. (eds.)(1995): Nationalism, Politics and the Practice of Archaeology. Cambridge University Press. Cambridge.

LANGFord, R. (1983): “Our Heritage Your Playground”. Australian Archaeology, 16: 1-6.

LAYTON, R. (ed.) (1989a): Who needs the Past? One World Archaeology, 5. Routledge. Londres.

- (1989b): Conflict in the Archaeology of Living Tradition. One World Archaeology, 8. Routledge. Londres.

LIPE, W. (1996): "Letter to the Editor of the New York Times". SAA Bulletin, 14(5): 4.

LÓPEZ MASS, J. (1990): "La reconstrucción del pasado, la identidad nacional y la labor arqueológica: El caso uruguayo". En G. Politis (ed.): Arqueología en América Latina Hoy. Biblioteca Banco Popular. Bogotá: 167175.

LOWENTHAL, D. (1990): “Conclusion: archaeologists and the others". En P. Gathercole y D. Lowenthal (eds.): The Politics of the Past. Unwin Hyman. Londres: 302-314.

Martínez Barbosa, R.(1996): El Ultimo Charrúa (de Salsipuedes a la actualidad). Rosebud. Montevideo.

McEwan, C.; Hudson, C. y Silva, M. (1994): “Archaeology and Community: A Village Cultural Center and Museum in Ecuador". Practicing Anthropology, 16(1): 3-7.

McManamon, F. (1995): "The Reality of Repatriation". Federal Archaeology, Fall/Winter: 2.

Miотт, L. (1994): "Inakayal. Un largo camino a Tecka". Boletín de la Secretaría de Extensión Universitaria. Facultad de Ciencias Naturales y Museo (UNLP). Octubre, 1994: 2-8.

Morell, V. (1995): “Who Owns the Past?". Science, 268: 1424-1426.

T. P., 57, n. ${ }^{\circ} 1,2000$ 
- (1998): "Kennewick Mans Trial Continue". Science, 280: 190-192.

Mulvaney, J. (1991): "Past regained, future lost: The Kow Swamp Pleistocene Burials". Antiquity, 65: 12-21.

Naranjo, T. (1994): “Guest Essay”. Native Peoples Magazine, Spring: 5.

ORMOND-PARKER, L. (1997): "A Commonwealth Repatriation Odyssey". Aboriginal Law Bulletin, 3 (90): 9-12.

Podgorny, I. (1991): "Historia, Minorías y Control del Pasado". Boletín del Centro, 2: 154-159.

PodGoRny, I. y MiotTi, L. (1994): "El pasado como campo de batalla". Ciencia Hoy, 5 (5): 16-19.

Podgorny, I. y Politis, G. (1992): “¿Qué sucedió en la historia? Los esqueletos araucanos del Museo de La Plata y la Conquista del Desierto". Arqueología Contemporánea, 3: 73-79.

Politis, G. (1992): "Política Nacional, Arqueología y Universidad en Argentina". En G. Politis (ed.): Arqueología en América Latina Hoy. Biblioteca Banco Popular. Bogotá: 70-87.

- (1994): "El regreso de Inakayal". Museo, 1(3): 46-48.

- (1995): "The socio-politics of the Development of Archaeology in Hispanic South America". En P. Ucko (ed.): Theory in Archaeology. A World Perspective. Routledge. Londres y Nueva York: 197-228.

Preucer, R. y Hodder, I. (1996): "Constructing Identities". En R. Preucel e I. Hodder (eds.): Contemporary Archaeology in Theory. A Reader. Blackwell. Oxford: 601-614.

QuATRIN DE RodrígueZ, Z. (1999): “Conflicto de Intereses en la Preservación del Patrimonio Cultural de Quilmes". Actas del XII Congreso Nacional de Arqueología Argentina (La Plata, 22-26 septiembre 1997), II: 316-320. La Plata.

REINHARD, J.(1999): "A 6,700 metros niños incas sacrificados quedaron congelados en el tiempo". National Geographic, 5(5): 36-55.

Simpson, M. (1994): "Burying the Past". Museum Journal, July: 28-32.

- (1997): Museum and Repatriation. An account of Contested items in Museum collections in the UK, with comparative material from other countries. The $\mathrm{Mu}-$ seum Association. Londres.

Slayman, A.(1997): "A Battle over bones: Lawyers Contest the Fate of an 8400-Year-Old Skeleton from Washington State". Archaeology, 50(1): 16.
Southworth, E. (1994): “A Special Concern”. Museum Journal, July: 23-25.

Stocking, G. (1988): "Bones, Bodies and Behaviour". En G. Stocking (ed.): Bones, Bodies and Behaviour. Wisconsin University Press. Wisconsin: 3-17.

Swedlund, A. y Anderson, D. (1999): "Gordon Creek Woman Meets Kennewick Man: New Interpretations and Protocols regarding the peopling of the Americas". American Antiquity, 64(4): 569-576.

Thомs, A. (1994): "Sacred Guardians, Profane Practitioners and Texans without History". En M. Campbell (comp.): The NAGPRA Workshop (Texas, 1-2 noviembre 1994). Museum of Texas University/ National Park Service. Lubbock. Texas.

TRIGGER, B. (1996): "Alternative Archaeologies: nationalist, colonialist, imperialist". En R. Preucer e I. Hodder (eds.): Contemporary Archaeology in Theory. A Reader. Blackwell. Oxford: 615-631. $1^{\text {a }}$ ed. 1984

TROPE, J. y EchO-HAWK, W. (1992): "The Native American Grave Protection and Repatriation Act: Background and Legislative History". Arizona State University Law Journal, 24: 35-77.

Uско, P. (1992): "Introduction". World Archaeological Bulletin, 6: 1-3.

Uско, P. (ed.) (1995): Theory inArchaeology. A world Perspective. Routledge. Londres y Nueva York.

VAsco URIBE, L. (1990): "Arqueología e identidad: El caso guambiano". En G. Politis (ed.): Arqueología en América Latina Hoy. Biblioteca Banco Popular. Bogotá: 176-191.

VÁzquez León, L. (1996): El Leviatán Arqueológico. Antropología de una Tradición Científica en México. Research School CNWS. Leiden.

WeBb, S. (1987): "Reburying Australian Skeletons". Antiquity, 61: 292-6.

WORLD Archaeological Bulletin, 4, 1989: 18-19.

WORLD Archaeological Bulletin, 5, 1991: 22-23.

ZIMMERMAN, L. (1987): "Webb on Reburial: a North American perspective". Antiquity, 61: 462-463.

- (1989a): "An opinion about some of the challenges and opportunities for archaeology and the osteological science offered at the WAC Inter-Congress". World Archaeological Bulletin, 4: 23-28.

- (1989b): "Made radical by my own: an archaeologist learns to accept reburial". En R. Layton (ed.): Conflict in the Archaeology of the Living Traditions. Routledge. Londres: 60-67. 